\title{
LAS DENOMINACIONES CORRESPONDIENTES A LAS LEXÍAS DE LA LENGUA ESTÁNDAR ARROYO, TORRENTERA, MANANTIAL Y TERRENO PANTANOSO EN ZAMORA, SALAMANCA Y ÁVILA (II)
}

\author{
Antonio Llorente Maldonado de Guevara \\ Universidad de Salamanca
}

4. "Terreno pantanoso". La pregunta fue formulada de la siguiente manera: ¿cómo llaman aqui al sitio que está siempre húmedo, rezumando agua, incluso en el verano, y que se encharca en cuanto llueve?

Las contestaciones a esta cuestión fueron numerosísimas y muy variadas, pero hay que hacer la siguiente salvedad: con frecuencia los informadores, como seguramente lo hubieran hecho todos los habitantes del pueblo explorado, no distinguian entre 'terreno pantanoso' y 'atolladero', significados muy próximos, como lo están también las realidades designadas. Como esta confusión es una confusión sistemática que no tiene carácter individual, hemos considerado válidas todas las contestaciones, con lo cual el número de las mismas se ha hecho muy grande, y nos encontramos con una extraordinaria riqueza de formas referidas al significado, y a la realidad, 'terreno pantanoso'.

El tipo léxico que aparece en mayor número de localidades es el constituido por bodón/bodonal/badonal/bonal, que encontramos en veintisiete localidades: bodón, en tres pueblos zamoranos (Ce., Cas., Po.); bodonal, en seis pueblos zamoranos ( $F e$., $C u$., $V e$., $P o$., Cea., To.), en cuatro salmantinos ( $P a ., V Y$., $V i l ., A A$.) y en el pueblo abulense de Pascualcobo; badonal, en dos pueblos zamoranos (Es., $B r$.); y bonal en once localidades, todas ellas salmantinas (Ped., Co., Alb., Sau., VR., AA., AG., Nav., Ro., Ci., Li.). 
Por el número de localidades le sigue el tipo léxico-etimológico trampal/ trampalera/trampaloso, que aparece en veinte puntos: trampal, en quince localidades abulenses (NA., Bl., Av., Al., Mg., Mi., Ho., SJ., NP., So., Bo., Na., Ti., Lan., Cand.) y una localidad salmantina (SB.); trampalera, en tres puntos de Ávila (Ga., Ho., Pie.); y trampaloso (seguramente terreno trampaloso) en el pueblo abulense de Bohoyo.

Con trece localidades aparece el tipo gotera/gotera remanosa, que encontramos en trece puntos: gotera, en diez localidades abulenses (Mad., NA., $B l$., $A v$., $M u$., Pasc., Al., Mg., Ga., NP.) y en dos salmantinas (Ta., $V G$.); gotera remanosa, en el pueblo abulense de Cantiveros.

Con ocho localidades, un conjunto de distintas formas que comienzan con chap-/chag- y terminan con los sufijos -al, -ero/-era: chapadal en dos pueblos zamoranos (Be., An.); chapatal, en Candeleda (Avila); chapazal en San Martín del Pedroso (Zamora); chaguazal, en San Martín de Castañeda (Zamora); chapacero, en dos pueblos zamoranos (Sa., Cea.); chapacera, en San Martín del Pedroso (Zamora).

Con cinco localidades, el tipo humedal/humedadal: humedal, en tres pueblos abulenses (NP., Ti., Lan.) ; humedadal, en dos localidades zamoranas (Cu., Ve.).

$\mathrm{La}$ forma sumidero fue registrada en dos pueblos zamoranos (Po., $B r$.) y dos salmantinos ( $A F$., $P A$.).

Tres localidades presentan el tipo lamacal/mamacal/llamazo, constituido por formas que se remontan al mismo lexema etimológico: lamacal, en Hermisende (Zamora); mamacal, en La Vidola (Salamanca); llamazo, en Folgoso de la Carballeda (Zamora).

También en tres puntos encontramos el tipo léxico-etimológico regajo/ regajar : regajo, en San Juan de la Nava (Avila) y en El Cerro (Salamanca); regaja, en Linares de Riofrío (Salamanca).

En dos localidades aparece ojero (So. -Avila-, SB. —Salamanca-); y la forma, creo que de la misma etimologia, oyuelo, en Espadañedo (Zamora).

También en dos localidades encontramos el tipo remanadal/remanadero: remanadal, en Andavías (Zamora); y remanadero, en Villabrázaro (Zamora).

Aguachal/Aguachinal son formas recogidas en dos localidades zamoranas: aguachal, en Fermoselle; aguachinal, en Venialbo.

Manantial/Manantialoso aparecen en dos localidades salmantinas: manantial, en Aldeaseca de la Frontera ; manantialoso (seguramente terreno manantialoso), en Villaverde de Guareña.

Tollero, es la contestación obtenida en dos pueblos salmantinos ( $P a$., Cerr.). 
Trimidera, la respuesta recogida en una localidad zamorana $(V a$. $)$ y otra salmantina $(P a$.).

Venero es la respuesta registrada en un pueblo zamorano (To.) y otro salmantino (Cerr.).

Fuentano y la variante fontanoso fueron las respuestas obtenidas en el pueblo salmantino de Herguijuela de la Sierra.

Barnil y barnial, las formas registradas en el pueblo zamorano de Villardiegua de la Ribera.

Badén, la contestación obtenida en Aldeavieja (Ávila), donde alterna con trampal.

Zampadal fue registrada en Tarazona de Guareña (Salamanca), junto con gotera.

Herrumblar es forma recogida en el pueblo abulense de Navacepeda de Tormes, al lado de trampal, como era de esperar.

En Alba de Yeltes (Salamanca) se registró juncal.

En Matilla la Seca (Zamora), fue registrada la voz resumadal.

En Ahigal de los Aceiteros (Salamanca), chupadero.

En Alameda de Gardón (Salamanca), guadaña.

En Villardiegua (Zamora), mesón (junto con barnil y barnial).

En Nava de Arévalo (Ávila), sagüero, alternando con otras formas.

En Alameda de Gardón, vagüero (alternando con guadaña, según dijimos más arriba).

La distribución geográfica de los distintos tipos léxico-etimológicos en que hemos agrupado las denominaciones del terreno pantanoso es muy interesante y sugeridora.

Así, por ejemplo, bodón y sus derivados son formas claramente occidentales, que aparecen en Zamora y Salamanca y en un solo pueblo abulense, Pascualcobo, en el extremo oeste de la provincia, en los límites de Salamanca. Y es curioso que la forma primitiva, bodón, se haya registrado únicamente en el norte de Zamora, lo mismo que el derivado anómalo badonal (seguramente cruce de bodonal y vado, o de bodonal y badén), mientras el derivado primario bodonal aparezca en las tres provincias, y el derivado secundario bonal ( $<$ bodonal $<$ bodón) sea exclusivo de Salamanca, y más concretamente de los dos tercios occidentales de la provincia.

$\mathrm{El}$ carácter occidental de bodón/bodonal/bonal se ve confirmado por los datos que nos proporcionan los repertorios léxicos, las monografías y los Atlas :

En primer lugar, no aparece ni en el Tesoro de Covarrubias, ni en el Diccionario de Autoridades ni en el DRAE, mientras G. de Diego consi- 
dera que bodón 'charco con espadañas' es forma propia de Avila, Segovia, Valladolid y Salamanca, bonal 'terreno fresco en un secano' forma caracteristica de Salamanca, y bodonal 'idem', forma usada en Valladolid y Salamanca ${ }^{81}$, y Martín Alonso cita bodón 'charca invernal que se seca en verano' sin localización geográfica, pero en cambio atribuye bodonal 'terreno encenagado' a Salamanca, y bonal 'idem' a Salamanca y Andalucía ${ }^{82}$, al tiempo que M. Moliner, siguiendo a Martín Alonso, tiene a bodonal 'terreno cenagoso o encenagado' como forma propia de Salamanca ${ }^{83}$.

En segundo lugar, bodón/budón son formas registradas en territorio leonés, como en Flores de Aliste, y en Pino de Duero (Zamora) ${ }^{84}$, y bodonal/bonal en Salamanca y en Extremadura ${ }^{85}$.

Además, y confirmando el dato de Martín Alonso, la variante bonal está registrada en Sierra Morena y Los Pedroches ${ }^{86}$, pero es inexistente en la zona oriental de Andalucia, como se ve en el mapa "terreno pantanoso" (lel $A L E A$.

Por último, no aparece ninguna de las formas del tipo bodón/bodonal/ bonal en los mapas "terreno pantanoso" y "barrizal" del $A L E A N{ }^{87}$, lo que quiere decir que esta familia léxico-etimológica es desconocida no sólo en Navarra, Rioja y Aragón sino en las comarcas, limítrofes con estas regiones, de Álava, Burgos, Soria, Guadalajara, Cuenca, Valencia y Castellón, o, lo que es lo mismo, la familia bodón/bodonal/bonal o no existe o no ha sido documentada en toda el área oriental del dominio lingüístico español.

Muy distinto es lo que ocurre con la fanilia léxico-etimológica trampal/ trampalera/trampaloso, que aparece, como sabemos, en veinte localidades, todas, menos una, localidades abulenses (y la única localidad no abulense donde aparece una contestación perteneciente a esta familia, concretamente la forma primitiva trampal, es una localidad del sureste de Salamanca, limítrofe con Avila, la localidad de Santibáñez de Béjar). Es decir, prácticamente la familia trampal/trampalera/trampaloso es exclusiva de la provincia de Ávila, lo que en principio nos permite suponer que se trata de un tipo léxico característico del área central del dominio lingüístico español (por otra parte las únicas localidades abulenses donde no aparece este tipo son los pueblos occidentales de Madrigal, Cantiveros, Pascualcobo y Muñico, todos ellos muy próximos a la provincia de Salamanca, o lindantes con ella).

81 Vid. Ciarcía de Diego, pág. 637.

82 Vid. Martín Alonso, I, págs. 729, 741.

83 Vid. M. Moliner. I, pág. 390.

* Vid. Ferrero, pág. 51; Borrego, pág. 78.

85. Vid. Lamano, págs. 289, 291; Viudas Camarasa, pág. 26.

86 Vid. A. Venceslada, pág. 94; ALE.4, IV, mapa 901.

87 Vid. ALE.4NR, X, mapas $1.376,1.388$. 
El carácter central, castellano, de trampal y sus derivados se confirma con los datos suministrados por los repertorios generales y los Atlas, sirviéndonos de muy poco las monografías regionales y locales, porque la circunstancia de aparecer trampal en el $D R A E$ ya desde su primera edición (Diccionario de Autoridades) hace que, considerada como forma general y estándar, no haya sido incluida en los vocabularios de carácter dialectal, regional o local.

De todas maneras, el área de trampal y sus derivados no debe de ser muy extensa, aunque aparezca en muchos repertorios generales, pero no en los anteriores al Diccionario de Autoridades, lo que resulta muy sintomático: porque la primera vez que encontramos trampal es en el Diccionario de Autoridades, donde se le da la significación de 'pantano, atolladero o lodazal' y se cita el siguiente pasaje de Santa Teresa (Fundaciones, 6): "trampal o atolladero" 88 . Santa Teresa, que como es sabido pasó una larga temporada en la comarca abulense de la Hoya del Barco, conocia perfectamente la palabra trampal, y lo que ésta designaba, y la empleó con la mayor espontaneidad en sus escritos, pero eso no quiere decir que sea una voz de uso general ni que lo fuera en su época. Es muy probable que si Santa Teresa no hubiera utilizado la palabra, o si los académicos dieciochescos no la hubiesen tomado como una autoridad, la voz trampal no figurara en los repertorios generales.

Del Diccionario de Autoridades la tomó Terreros, que seguramente no usaba la palabra ${ }^{89}$, y después la han tomado, e incluido en sus repertorios, Corominas $^{90}$, Martín Alonso ${ }^{91}$ y Maria Moliner ${ }^{92}$ y, por supuesto, ha seguido apareciendo en las sucesivas ediciones del DRAE.

Es muy revelador que hallemos trampal en Andalucía, prolongación natural del área castellana o central del dominio lingüístico español: trampal es la respuesta a la cuestión "terreno pantanoso" que encontramos en un punto de la zona oriental, serrana, de Cádiz y en dos localidades de la comarca cordobesa de Los Pedroches, al norte de Sierra Morena ${ }^{93}$.

$\mathrm{Y}$ más revelador, todavia, que no aparezca trampal, ni ninguno de sus derivados, en ninguno de los puntos explorados de Navarra, Rioja, Aragón. Alava, Soria, Guadalajara, Cuenca, Valencia, Castellón ${ }^{n 4}$.

88 Vid. Diccionario de Autoridades, 1II, 2, pág. 323.

89 Vid. Terreros, III, pág. 682.

9o Vid. Corominas-Pascual, V, págs. 590-591 (aparece la palabra trampal con el significado 'atolladero', y la referencia a Avila, a Santa Teresa y al Diccionario de Autoridades).

91 Vid. Martin Alonso, III, pág. 4.008.

02 Vid. M. Moliner, II, pág. 1.359 .

93 id. ALEA, IV, mapa 901.

94 id. ALEANR, X, mapas $1.376,1388$. 
También resulta muy interesante la repartición geográfica y la extensión del área de gotera/gotera remanosa.

Como hemos dicho, el área de estas dos formas es un área, bastante compacta, que abarca la mitad septentrional de la provincia de Ávila y el extremo nordeste de Salamanca. El área real de gotera debe de ser mucho mayor, incluyendo, por lo menos, el tercio oriental de la provincia salmantina y el sureste de Zamora, aparte de su probable difusión por las provincias de Valladolid y Segovia, provincias no exploradas por nosotros. Y digo esto, porque en muchos pueblos del norte y del este de Salamanca he oído la voz gotera, fuera de mi trabajo como encuestador, referida a los terrenos aparentemente secos en el invierno pero con mucha agua subterránea superficial, casi a flor de tierra, lo que hace que no se pueda pisar en ellos porque las personas, los animales y los vehículos se hunden y se atollan en seguida. Es decir, gotera no es, por lo menos en Salamanca, exactamente igual que bonal o que terreno pantanoso, aunque sean realidades muy próximas. No es exactamente igual porque el bonal está húmedo incluso en el verano, y la gotera en el verano desaparece, además de que cuando se habla de goteras nos referimos generalmente a terrenos de labor no a eriales o a terrenos de pastos.

Todo esto explica que en la mayor parte de los puntos donde se ha registrado gotera los informadores dieran otra $\mathrm{u}$ otras contestaciones, como trampal, trampalera, bodonal, ojero, manantialoso, badén, zampadal, sagüero.

La forma que si responde fielmente a la cuestión "terreno pantanoso" es la lexía compleja gotera remanosa, es decir, 'gotera que escupe el agua encharcando el terreno', lexía registrada en el pueblo abulense de Cantiveros.

No podemos saber si gotera, con las significaciones a que hemos hecho referencia, existe en alguna otra área del dominio lingüístico español. Como no aparece en ninguna monografía, ni en ningún Atlas, ni siquiera en los repertorios generales, no es factible aventurar una opinión, pero pienso que es más que probable que nos encontremos delante de una palabra exclusiva de Ávila, Salamanca, Zamora y comarcas limítrofes, a lo sumo frente a una forma utilizada sólo en la Meseta Norte y en las serranías carpetovetónicas.

Hay una serie de denominaciones del terreno pantanoso que comienzan por chap-, chag- y terminan con los sufijos -al, -ero/-era, denominaciones todas ellas de carácter onomatopéyico, lo mismo que determinados sustantivos primitivos de los que se derivan o con cuya raiz están relacionados, como chapallo 'barro, lodo, fango', y que determinados verbos de la misma familia, como chapotear, chapalatear, chapallar, etc. Estas denominaciones, 
algunas de las cuales son el resultado de un cruce de palabras, o de la suma de dos elementos (cha/chap + agua $>$ chaguazal) se han registrado sólo en pueblos zamoranos y en el pueblo más suroccidental de la provincia de Ávila, en Candeleda, es decir, parecen formas caracteristicas del área occidental, leonesa, lo que en parte se ve confirmado por el hecho de que, a pesar de no haber aparecido en las encuestas (quizá a consecuencia de responder más que al significado de 'terreno pantanoso' al significado de 'atolladero, barrizal, lodazal'), son habituales en gran parte de la provincia de Salamanca, especialmente en la mitad occidental.

Las formas de esta familia son, como sabemos, chapadal, chapatal, chapazal, chaguazal, chapacero, chapacera. De todas ellas, sólo una aparece en los repertorios generales, y no en todos, la denominación chapatal, a la que el $D R A E$, García de Diego y Martín Alonso le atribuyen la significación de 'ciénaga; barrizal; lodazal ; pantano' ${ }^{95}$. Por cierto chapatal fue registrada en Candeleda, fuera ya del dominio propiamente leonés, lo que confirma el carácter castellano atribuido a esta forma por García de Diego y Martín Alonso.

El resto de las denominaciones de este grupo no están documentadas en los repertorios generales, y son claramente occidentales, algunas de ellas comunes al dominio galaico-portugués y al dominio leonés, como chapazal $(P e$.$) , en portugués, chapaçal y chapacero (Sa., Cea.), chapacera (P e$.), en portugués transmontano (como en el caso anterior), chapaceiro ${ }^{97}$.

Por lo que hace a las denominaciones restantes de las pertenecientes a este grupo, chapadal (Be., $A n$.) no aparece en ninguna monografía ni en ningún vocabulario regionales, mientras chaguazal (Cas.) encuentra un paralelo en el verbo enchaguazar 'encharcar', usual en el Bierzo leonés ${ }^{88}$ y que en Salamanca, según mi experiencia fuera de encuestas, adopta la variante enchaguarzar/enchaguarzarse.

En relación con las denominaciones del grupo que acabamos de estudiar se hallan las formas aguachal/aguachinal registradas en dos localidades zamoranas, la primera en Fermoselle, y la segunda en Venialbo, es decir, ambas en el sur de la provincia. Estas voces, de mucho uso en el dominio leonés, atestiguadas en este dominio repetidamente con anterioridad a las encuestas $^{{ }^{\circ}}$, parecen ser voces más o menos generales en todo el dominio lin-

95 Vid. García de Diego, pág. 713; Martin Alonso, I, pág. 1.332. (Según M. Alonso chapatal aparece ya en el xvi, en una obra del castellano viejo Villalobos).

96 Vid. Figueiredo, I, pág. 541.

97 Vid. Figueiredo, I, pág. 541.

98 Vid. García Rey, pág. 86.

99 En la Maragatería, aguachinar 'encharcar' (vid. Alonso Garrote, pág. 134); en Salamanca, aguachinar 'llenarse las tierras de agua; encharcarse' (vid. G. de Diego, pág. 599; Lamano, pág. 197); en Extremadura, aguachinao/aguachinau 'encharcado/ 
güísticu español, tanto en el metropolitano como en el ultramarino ${ }^{100}$, y lo mismo en el área leonesa occidental, que llega hasta Huelva, que en el área central, que en el área oriental que se extiende desde Navarra, Rioja y Aragón hasta Andalucia oriental ${ }^{101}$.

También en relación con los grupos anteriores (por presentar las característica común de ser denominaciones formadas con el sufijo derivativo abundancia -al) se encuentra el tipo humedal/humedadal.

El subtipo humedal sólo aparece en localidades abulenses, y el subtipo (con el interfijo reiterativo-expresivo -ad) humedadal, sólo en dos localidades zamoranas.

El hecho de aparecer humedal en pueblos abulenses, en pueblos abulenses de la mitad oriental de la provincia, además, parece apuntar al carácter castellano, o central, de esta voz, y a la probabilidad de que sea considerado el vocablo como voz general o perteneciente al estándar, y, efectivamente, humedal es voz usada hoy por geógrafos, ecólogos, geólogos, edafólogos, etc., como voz no sólo general, sino de carácter técnico, para designar todos los lugares húmedos de España, como lagunas, zonas pantanosas, turberas, marismas, zonas endorreicas, etc.

En el DRAE, humedal es definida como 'terreno húmedo', sin localización geográfica, y, a juzgar por los datos que nos proporcionan los Atlas, es voz preferentemente del área central del dominio lingüistico español, que

terreno pantanoso' (vid. Viudas Camarasa, pág. 4); en la comarca del Barco de Avila, limitrofe con Salamanca, aguachinar 'llenarse de agua un alimento' (vid. Nicolás de la Fuente Arrimadas, Fisiografia e Historia del Barco de Avila (I-II; Avila, 1925-1926, Vocabulario, tomo II, págs. 377-386), II, pág. 377; incluso en portugués encontramos una forma de esta familia, la voz ayuaçal 'pantano' ( vid. Morais, I, pág. 497).

100 En el DRAE, aguachar 'charco'; según G. de Diego, cast. aguachar 'encharcar' (vid. G. de Dicgo, pág. 599); Terreros nos dice que "aguacharse es voz de labradores, y significa llenarse de agua con demasía las plantas y la tierra" (vid. Terreros, I, pág. 44); según Corominas, aguachinar 'encharcar' es voz usada en Aragón y en Venezuela (vid. Corominas-Pascual, I, pág. 79); para M. Moliner, que no indica ninguna localización geográfica, aguachar 'charco', y también 'enaguazar, encharcar' (vid. M. Moliner, I, pág. 93).

101 En el Diccionario de Autoridades encontramos: "aguadinar, llenar de agua algún pedazo de tierra, enaguazar. Voz baxa usada en Aragón" (vid. Diccionario de Autoridades, I. 1, pág. 126); Según Martín Alonso, aguachal 'aguachar, charco', en Burgos y Medina (vid. Martin Alonso, I, pág. 174); para M. Moliner, aguachinar 'enaguazar, aguacharnar', en Aragón y Salamanca (vid. M. Moliner. I, pág. 93); también para G. de Diego aguachinar 'llenarse las tierras de agua', es voz usada en Aragón (vid, G. de Diego, pág. 599).

En el norte de Huelva y noroeste de Sevilla encontramos aguachinoso y enguachinoso, y cnguachinao también en Huelva (vid. ALEA, IV, mapa 902), mientras aguarchal aparece en Granada (vid. ALEA, IV, mapa 901), aguachal/aguarchal en el sur de Navarra y en el sur de Teruel, y aguachinal, aguarchinal, aguarchinao en Navarra, Rioja Alavesa, Rioja Baja (vid. ALEANR, X, mapa 1.388).

102 Vid. ALEA, IV, mapas 901, 902. 
por el sur se ha extendido hasta las provincias centro-orientales de Andalucía (Córdoba, Málaga, Granada, Jaén) ${ }^{102}$, y por el oriente hasta la franja occidental de Zaragoza, Teruel y Valencia, incluyendo, por supuesto, las zonas, limítrofes con Aragón y Reino de Valencia, de las provincias de Soria, Guadalajara y Cuenca ${ }^{103}$.

Por lo que respecta a humedadal, variante registrada sólo en los pueblos zamoranos de El Cubo del Vino y de Venialbo, en el sureste de la provincia, no aparece en ninguna de las obras consultadas ni en ninguno de los Atlas, y parece una creación local, o mejor dicho comarcal, de la comarca de La Tierra del Vino a que ambos pueblos pertenecen.

Un caso especial es el representado por lamacal/mamacal/llamazo, formas todas ellas atribuibles a la raiz prerromana, propia del occidente peninsular, lam-, que presenta derivados en todas las hablas occidentales hispánicas tanto del dominio lingüístico galaico-portugués como del dominio español.

Lamacal, registrada en Hermisende, encuentra correspondencia en muchas hablas del occidente, alguna vez correspondencia exacta, como en el caso de la localidad zamorana de Lubián, también de habla galaico-portuguesa, donde aparece lamacal 'terreno encharcado y barroso' ${ }^{104}$, otras veces correspondencia relativa, como en las formas portuguesas lamaçal, lamaço. lamą̧ar 'terreno pantanoso' 105, las gallegas lamazal, lamegal 'lodazal' 104 y la castellana occidental lamazal 'barrizal' ${ }^{107}$.

$\mathrm{La}$ forma mamacal, registrada en el pueblo sahmantino occidental de $\mathrm{La}$ Vídola, evidentemente es una deformación, por etimología popular (influencia de mamar) de la forma lamacal, lo que quiere decir que antiguamente, y quizá hoy todavía en algún punto aislado, lamacal ocupaba un área occidental extrema que iría desde La Cabrera Baja y Sanabria hasta el oeste de Salamanca, incluso de Cáceres.

Por lo que respecta a llamazo, respuesta obtenida en el pueblo zamorano de Folgoso de la Carballeda, cuya habla es un habla leonesa occidental típica, como la de San Martín de Castañeda, nos encontramos con un ejemplo del fenómeno típicamente leonés, y hoy sobre todo leonés occidental, de palatización de $l$ - inicial de palabra o de sílaba, fenómeno que no ocurre en las hablas del dominio galaico-portugués ni siquiera en las hablas galaicoportuguesas de Sanabria y Tras-os-Montes.

Formas paralelas a llamazo, también con palatalización de la inicial, en-

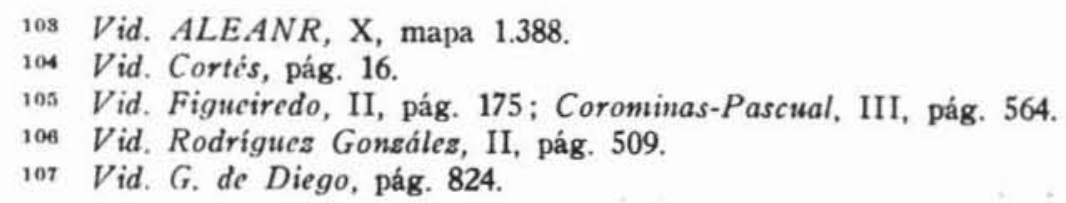


contramos en gran parte del dominio lingüistico leonés, como llamazar, incluso en Asturias, donde llama no sólo significa 'lodo, barro', como la forma castellana occidental lama, sino también 'terreno pantanoso' ${ }^{108}$, y donde aparece, además, la variante llamaza ${ }^{109}$.

Voces relacionadas también con las anteriores, por presentar, asimismo, el sufijo derivativo-abundancial -al (-ar) son zampadal, registrada en el pueblo salmantino de Tarazona de Guareña, y herrumblar, contestación obtenida en la localidad abulense de Navacepeda de Tormes:

Respecto a la primera, que no se repite en ninguno de los pueblos explorados ni hemos encontrado en ningún repertorio ni ningún Atlas, sólo se puede decir que es una creación local, análoga a todas las formaciones sinónimas con sufijo -al, hecha sobre zampar, zamparse 'hundirse en el fango, atollarse'.

Por lo que hace a herrumblar, que tampoco aparece registrada ni documentada en ninguna obra, es una forma curiosa e interesante, que se puede explicar por el hecho de que en los sitios húmedos, pantanosos, es muy fácil que aparezca herrumbre, que las herramientas, incluso las propias plantas se oxiden y corrompan, o quizás porque el agua estancada en determinados parajes donde haya óxido de hierro o materiales ferruginosos adquiera sabor a herrumbre y también un cierto color rojizo ${ }^{110}$.

Encontramos también el sufijo derivativo-abundancial -al en la forma resumadal, registrada en Matilla la Seca (Zamora), que parece relacionada con el verbo del español común rezumar 'dejar pasar gotas a través de los poros', que encontramos en todos los repertorios generales, y con las voces de carácter regional, que citamos a continuación, la hispanoamericana resumir 'gotear' ${ }^{111}$, la salmantina resumir 'rezumar' 112 y la extremeña rezumir 'rezumar, gotear' ${ }^{113}$. En todo caso, resumadal parece una voz del área occidental del doninio lingüístico español, es decir, del área leonesa, y no es de extrañar que no aparezca en ninguno de los repertorios, de las monografías y de los Atlas consultados.

Las que sí aparecen, y concretamente en el $A L E A$, son las voces, formadas con el sufijo -ero, sumidero y resumidero, que podrían estar relacionadas con la anterior ( $\mathrm{y}$, por lo tanto, con resumir 'rezumar'), y una de cuyas

108 Vid. Corominas-Pascual, III, págs. 564-565.

109 Vid. G. de Diego, pág. 824.

110 En el DRAE herrumbrar aparece con la definición 'producir herrumbre', y según M. Moliner, herrumbre, además de 'óxido de hierro, rubín' significa también 'sabor de hierro que toman las cosas, por ejemplo el agua, que están en contacto con él' (vid. M. Moliner, II, pág. 36). Lo mismo dice de herrumbre Martín Alonso (vid. $M$. Alonso, II, pág. 2.256).

111 Vid. Corominas, DCELC, IV, pág. 875.

112 Vid. Lamano, pág. $613 ;$ G. de Diego, pág. 1.003.

11 s Vid. Corominas, DCELC, IV, pág. 875. 
dos variantes, sumidero, fue la respuesta obtenida en dos pueblos salmantinos y otros dos zamoranos a la cuestión "terreno pantanoso". El carácter occidental de sumidero es innegable, porque, por un lado, esta voz no fue registrada en ningún pueblo de Ávila, y, por otra parte, no sólo sumidero sino también resumidero, de la que puede proceder la anterior a consecuencia de la aféresis silábica causada por etimologia popular, aparecen en varias localidades de Huelva, Sevilla, Cádiz, Málaga ${ }^{114}$ mientras son totalmente desconocidas en el resto de Andalucía, y en Navarra, Rioja, Aragón y comarcas limitrofes de Alava, Burgos, Soria, Guadalajara, Cuenca, Valencia y Castellón ${ }^{115}$.

En sólo dos localidades, ambas zamoranas ( $A n$., $V i$.), encontramos derivados de remanar, los dos con el interfijo intensivo - ad-y cada uno de ellos con un sufijo derivativo distinto $(-a l ;-$-ero $)$ : remanadal, en Andavías, y remanadero en Villabrázaro.

Sobre remanadal 'manantial' ya hemos hablado en el apartado correspondiente. Según dijimos entonces, tanto remanadal como remanadero, y lo mismo en el significado de 'manantial' que en el significado de 'terreno pantanoso' son igual que remanar 'seguir manando, rezumar', formas preferentemente occidentales ${ }^{116}$, aunque el área de remanadero incluya no sólo Andalucía occidental sino también Córdoba y el oeste de Jaén ${ }^{117}$. Ni remanadero ni remanadal aparecen en el área oriental del dominio lingüistico español ${ }^{118}$.

Otra forma con sufijo de tipo -al, -ar encontramos entre las respuestas a la cuestión "terreno pantanoso", la voz regajar, registrada en Linares de Riofrío (Salamanca), voz derivada de regajo, que, con la misma significación, aparece en un pueblo abulense (San Juan de la Nava) y en el pueblo serrano salmantino de El Cerro.

Teniendo en cuenta que tanto Linares como El Cerro se encuentran en el tercio oriental de la provincia, y que San Juan de la Nava se halla en el este de Avila, parece sensato pensar que regajo/regajar es un tipo característico del área centro-occidental del dominio lingüístico español. Pero los datos que nos proporcionan las monografías, repertorios y Atlas no confirman esta impresión: regajo y regajar/regajal, con distintas significaciones, todas ellas próximas ('charco; hondonada húmeda, arroyuelo; laguna') son voces documentadas en Berceo, y que aparecen sin localización geográfica

114 Vid. ALEA, IV, mapas 901, 902.

$115 V$ id. ALEANR, $\mathrm{X}$, mapa 1.388.

11 Vid. Lamano, pág. 608; Alonso Garrote, pág. 308; G. de Diego, pág. 940; Corominas-Pascual, III, pág. 795; M. Moliner, II, 990; Borrego, pág. 77; M. Alonso, III, pág. 3.573 .

117 Vid. ALEA, IV, mapa 901.

118 Vid. ALEA, IV, mapas 894, 901; ALEANR, X, mapas 1.382, 1.388. 
en los repertorios de la RAE, Terreros y Martín Alonso ${ }^{119}$; además, y esto es lo verdaderamente importante, regajo, con el significado de 'arroyo', no asi regajar (que parece hoy forma preferentemente occidental), es voz existente no sólo en Andalucia occidental (Huelva, Sevilla, Cádiz, oeste de Málaga) y central (Córdoba) ${ }^{120}$, sino que aparece con cierta frecuencia en el suroeste de Navarra, oeste de la Rioja, sur de Teruel y zona de Segorbe ${ }^{121}$.

Lo que sí parece claro es que regajo, con el significado de 'terreno pantanoso' o el de 'hondonada húmeda' ${ }^{122}$ o el de 'prado húmedo', que tiene en Herguijuela de la Sierra (según las encuestas) y en toda la zona serrana de Salamanca (según mi experiencia personal), regajo con estos significados, repito, es o parece ser forma exclusiva del centro-oeste peninsular.

Sobre manantial/manantialoso, formas registradas en dos pueblos del nordeste de Salamanca no merece la pena de añadir nada a lo que ya comentamos al tratar de las respuestas a la cuestión "manantial", y tampoco parece necesario comentar la voz juncal registrada en Alba de Yeltes (Salamanca), pues la identificación, y la confusión, entre juncales y junqueras, por un lado, y terrenos encharcados y pantanosos, por otro, es algo habitual en todo el dominio lingüístico español.

Varias de las denominaciones del terreno pantanoso, entre las que todavía no hemos analizado, presentan como característica común el haberse formado con el sufijo derivativo-abundancial -ero/-era, el mismo que encontrábamos en trampalera, gotera, chapacero/chapacera, sumidero, remanadero.

Estas formas que quedan por estudiar son chupadero, sagüero, tollero, trimidera, vagüero, venero, ojero.

Respecto a chupadero, forma registrada en el pueblo salmantino de Ahigal de los Aceiteros, poco o nada se puede decir: se trata de una creación comarcal o local, no atestiguada en ningún otro sitio, y no se ve una relación clara entre el significado de chupadero y el significado de la palabra primitiva chupar, a no ser que con aquella palabra hayan querido referirse al hecho de que el agua se acumula en un determinado paraje porque allí hay una fuerza que la succiona, que la "chupa", que la atrae, por tratarse de una depresión.

Sagüero, contestación obtenida en el pueblo abulense de Nava de Arévalo, zona endorreica, puede ser un derivado, con aféresis, de desaguadero, o un cruce de desagüe y desaguadero, con aféresis posterior. Esta forma tampoco está atestiguada en ninguna parte, y debe de ser también una for-

119 Vid. Martín Alonso, III, pág. 3.556; Terreros, III, pág. 319; DRAE, página 1.121 (ed. año 1970).

$120 V$ id. $A L E A$, IV, mapa 883.

121 Vid. ALEANR, X, mapa 1.374.

122 Vid. Lamano, pág. 604; Martín Alonso, III, pág. 3.556. 
mación comarcal o local, explicable de manera semejante a la anterior, es decir, sagïero 'paraje donde se acumulan las corrientes procedentes del desagüe de los terrenos circundantes, y que no tienen salida, por tratarse de una depresión endorreica'.

Tollero, en cambio, es transparente. Se trata de un derivado abundancial de tollo, forma que con el significado de 'lodo, fango' aparece en el $D R A E$ como propia de León y Salamanca, y con el significado de 'tremedal' como voz general, cosa dudosa, y que ha sido registrada también en El Bierzo, no sólo con el significado de 'barro, lodo', sino con el de 'atolladero' ${ }^{123}$. Tollero 'atolladero, trimidera' es forma muy usada en Slamanca, ${ }^{124}$, por lo que no es de extrañar que en las encuestas haya sido registrada sólo en localidades salmantinas, concretamente en Palacios del Arzobispo (norte de la provincia) y El Cerro (extremo meridional de Salamanca). Según mi experiencia personal anterior a las encuestas, tollero es forma usual en prácticamente toda la provincia, con el significado de 'atolladero', y, secundariamente, con el de 'terreno encharcado o húmedo', y probablemente será forma habitual también en las provincias vecinas de Zamora, Avila, Cáceres, por lo menos en las comarcas más próximas a Salamanca; y en toda la región, todos los cazadores conocen el infalible refrán siguiente: "En Enero, busca la liebre en el tollero".

Tollero no aparece en los repertorios generales (sólo en el de Martín Alonso, y como forma propia de Salamanca), y tampoco en los Atlas, ni siquiera en Andalucía occidental, ni tampoco en Aragón, a pesar de que, según el $D R A E$, tollo, con el significado de 'charco', es voz usual en Aragón.

En definitiva, parece que tanto tollo como tollero son formas preferentemente occidentales, sobre todo la forma derivada, tollero.

Trimidera es voz registrada en el pueblo zamorano de Vadillo de la Guareña y en la localidad salmantina de Palacios del Arzobispo, donde, por cierto, y como acabamos de ver, alterna con el sinónimo tollero. Derivada, como la voz más extendida tremedal, de tremer 'temblar', la forma tremidera y sus variantes tremedera y trimidera son voces atestiguadas, a lo que yo sé, exclusivamente en Salamanca ${ }^{125}$, aunque es evidente que se usan, por lo menos, en la parte meridional de Zamora, y quizá en el resto de la provincia zamorana, donde encontramos variantes de la misma familia, como tremedal, en San Ciprián de Sanabria ${ }^{126}$, e incluso en León, pues en Bercianos del Real Camino se ha registrado la voz tremedal ${ }^{127}$.

123 Vid. García Rey, pág. 150.

124 Vid. Lamano, pág. 644; Martín Alonso, III, pág. 3.977. pág. 4.043 .

125 Vid. Lamano, págs. 648-649; G. de Diego, pág. 1.027; Martín Alonso, III,

126 Vid. F. Krüger, El dialecto de San Ciprián de Sanabria. Monografía leonesa, Anejo IV de la RFE, Madrid, 1923, pág. 128. 
Es curioso, por otra parte, que en ninguno de los puntos explorados haya sido recogida la voz, más extendida y más general, tremedal, a pesar de que en las cercanías de varias de las localidades exploradas en Salamanca hay un pueblo que se llama Tremedal de Tormes, topónimo éste, Tremedal, que se repite en varias regiones del dominio lingǘstico español, como, p. e., en Guadalajara, donde existe un pueblo, en el mismo limite con Teruel, que se llama Orihuela del Tremedal.

Aunque no aparece en ninguno de los Atlas, tremedal es voz considerada voz general, la encontramos en todos los repertorios sin localización geográfica, y aparte de los testimonios de la toponimia debió de ser forma muy generalizada, pues aparece ya en Ambrosio de Morales como sinónimo de laguna cenagosa, según vemos en el Diccionario de Autoridades ${ }^{128}$.

Vagüero es forma recogida en el pueblo salmantino de Alameda de Gardón, contestación no muy apropiada pues, como vimos al tratar de la cuestión "torrentera", vagüero, forma recogida en Villaseco de los Reyes, es una variante diminutiva de vagïera, la denominación usual en Salamanca para el significado 'vaguada', y, por lo tanto, vagüero apunta realmente a una vaguada o a un barranco pequeños, sobre todo de poca anchura, aunque puedan ser relativamente hondos. $\mathrm{Y}$, naturalmente, en toda vaguada, $\mathrm{u}$ hondonada, si es profunda y no tiene mucha pendiente, puede acumularse el agua y empantanarse, lo que explica la respuesta vagüero obtenida en Alameda de Gardón respecto a la cuestión "terreno pantanoso". En todo caso, y como ya sabemos, vagüera/vagüero es un tipo léxico occidental, registrado casi exclusivamente en Salamanca.

Venero, con el significado de 'terreno pantanoso', es forma registrada en el pueblo zamorano de Torrefrades y el salmantino de El Cerro.

Como vimos al estudiar las contestaciones a la cuestión "manantial", en tres pueblos abulenses fue recogida la voz venero, vocablo registrado con otras significaciones también en pueblos de Salamanca, Zamora y Extremadura (venero o, en su caso, la variante venerio).

El hecho de que venero 'terreno pantanoso' sea forma registrada en pueblos de Zamora y Salamanca refuerza la opinión formulada al estudiar las denominaciones referidas a "manantial", según la cual venero es voz del área centrooccidental del dominio lingüistico español.

Hemos dejado para el final, dentro del grupo de denominaciones en -ero, la forma ojero, registrada en dos pueblos de la comarca del Alto Tormes, a caballo entre las provincias de Avila y Salamanca: En Solana de Béjar (actualmente provincia de Avila, pero con anterioridad perteneciente a Salamanca) y Santibáñez de Béjar (Salamanca).

127 Vid. Aguado, pág. 198.

128 Vid. Diccionario de Autoridades, III, 2, pág. 348. 
Como es bien sabido, ojo es una palabra castellana, calco de la correspondiente voz arábiga, que está documentada desde la Baja Edad Media con el significado de 'manantial', que está muy extendida por la toponimia (Ávila, Segovia, Ciudad Real, Murcia) y que, como apelativo, ha sido registrada en el Alto Aragón, Andalucía y América ${ }^{129}$, de la misma manera que ocurre en portugués con olho d'água ${ }^{130}$.

Ojo debió de significar, en un principio, 'cada uno de los sitios donde brota el agua en un manantial', y de ahí que ojero sea un abundancial que aluda al conjunto de ojos, de chorros, que forman un manantial, y, por lo tanto, al manantial en su conjunto. Y lo mismo ocurre en portugués, donde al lado de olho d'água encontramos olheiro 'nascente de água' ${ }^{131}$. Como en algunos repertorios se especifica que ojo hace referencia no a cualquier tipo de manantial sino al "manantial que surge en un llano" ${ }^{132}$, no tiene nada de particular que ojero haya pasado a significar 'terreno pantanoso', primero por su carácter abundancial, y, sobre todo, porque al brotar el agua en un llano la zona donde surge el agua se encharca con facilidad. Es muy interesante y sintomático que en portugués provincial de la Beira olheiro signifique, como ojero, no 'manantial' sino también 'terreno pantanoso' ${ }^{13 s}$.

Veiamos antes que, según Corominas, ojo 'manantial' existía en Aragón y en Andalucia. Pues bien, los Atlas confirman la aseveración de Corominas, pues ojo de agua 'manantial' es lexía registrada en Huelva y en Cádiz ${ }^{134}$, y ojo 'manantial', forma recogida en un pueblo del occidente de Teruel ${ }^{135}$. Ahora bien, ni en Atlas ni en repertorios ni en monografías aparece el derivado ojero 'terreno pantanoso' registrado en los dos pueblos de Ávila y Salamanca.

Habíamos dejado para el final el estudio de ojero porque hay otra denominación del terreno pantanoso, que no presenta el sufijo -ero, pero que indudablemente pertenece a la misma raiz de ojero, es decir, a ojo, o mejor dicho a oculu, pues se trata de la denominación oyuelo 'terreno pantanoso' registrada en el pueblo zamorano de Espadañedo (Carballeda), forma que no puede ser otra cosa que un diminutivo de ollo/oyo 'ojo', sin diptongación de la $o$ breve ante yod (como sería de esperar en leonés) por hallarse en posición átona. Es decir, oyuelo, en mi opinión es un diminutivo de la forma leonesa uello/ucyo, que además de la significación 'ojo' tendría el signifi-

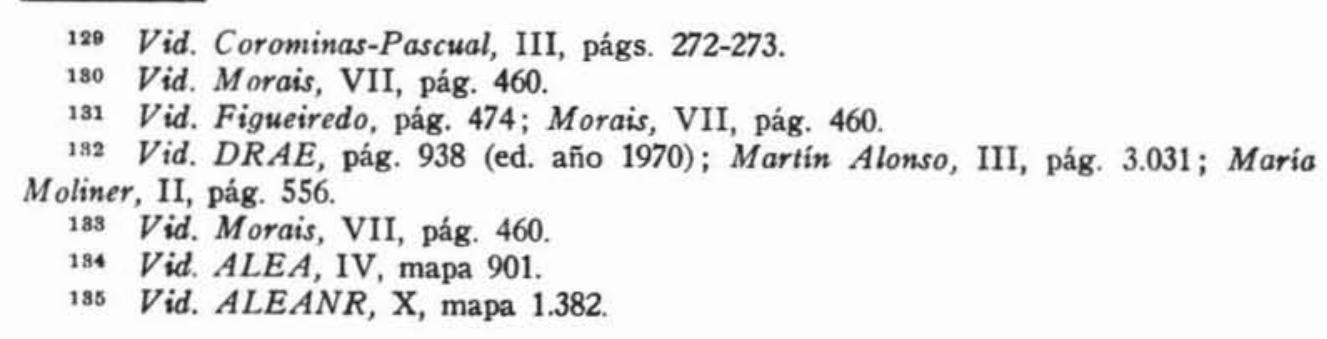


cado 'manantial', como la forma castellana correspondiente. La ubicación geográfica de Espadañedo, en plena área del leonés occidental, avala nuestra opinión.

Es muy significativo, en apoyo de nuestra interpretación de oyuelo (que, precisamente porque no tiene nada que ver con hoyo, transcribimos $\sin h$ ) que en el pueblo zamorano, alistano, de San Vitero (también en el área del leonés occidental) haya sido registrada la voz iyuelo 'manantial' ${ }^{136}$.

$\mathrm{Y}$, para terminar, el resto de las formas registradas como respuestas a la cuestión "terreno pantanoso", que son las siguientes: fuentano/fontanoso; barnil/barnial; badén; guadaña; mesón.

Respecto a fuentano/fontanoso, formas recogidas en el pueblo zamorano de Hermisende, de habla galaico-portuguesa, poco hay que decir, y que añadir a lo que ya expusimos en relación con las formas fontano/funtano 'manantial' recogidas por J. Carlos González Ferrero en su monografía sobre el habla de Flores de Aliste. Si acaso, que fontano, a pesar de las apariencias, no es forma exclusivamente occidental, pues Terreros la recoge en su repertorio con el significado de 'fontanal, lugar donde hay muchas fuentes' ${ }^{137}$; este significado explica el de 'terreno pantanoso' que fuentano (seguramente ultracorrección, por fontano/funtano), fontanoso tienen en Hermisende, pues 'lugar donde hay muchas fuentes' hay que entenderlo como 'lugar donde surgen muchos manantiales', es decir, 'lugar que está siempre encharcado'.

Barnil/barnial son formas registradas en el pueblo zamorano de Villardiegua de la Ribera, en el noroeste de Sayago, limitrofe con Portugal y con El Aliste. Formas idénticas, o semejantes, sólo han sido recogidas en el pueblo rayano de Villadepera de Sayago, donde aparecen barnial/barnizal con el significado de 'terreno pantanoso; barrizal' ${ }^{138}$. Como parece muy raro que estas formas sean exclusivas del pequeño rincón del noroeste de Sayago constituido por los términos municipales de Villadepera y Villardiegua, es de suponer que existan también en otros puntos de Sayago, y quizás del Aliste y de la zona limítrofe de Miranda do Douro. Sin embargo, no aparecen en ningún repertorio ni monografía, aparte del estudio sobre Villadepera.

La única explicación posible de estas formas, desde el punto de vista fonético, pues no parece plausible pensar en una etimología especial (prerromana, p. e.) es suponer la existencia de una alternancia $r n / r r, r r / r n$, semejante a la existente en el territorio pirenaico con sustrato vasco o paravasco, entre $r d$ y $r r, r r$ y $r d$.

13e Vid. Baz, pág. 95.

187 Vid. Terreros, II, pág. 176.

138 Vid. Borrego, pág. 78. 
Parece, de todas formas, evidente que barnil/barnial equivalen a barril/ barrial, y que, por lo tanto, significan, en principio, 'barrizal, lodazal, fangal', significados de los que se pasa fácilmente al de 'terreno encharcado; terreno pantanoso'.

La presunta variante * barril 'barrizal' no la he encontrado documentada, pero, en cambio, barrial aparece ya en Terreros, con el significado de 'barrizal' 139, significado con el que encontramos esta forma en el $D R A E$, con la indicación de "anticuada" $\mathrm{y}$ de ser usual todavía en América ${ }^{140}$. La referencia a su uso americano aparece también en los repertorios de Martín Alonso ${ }^{141}$, María Moliner ${ }^{142}$ y Corominas-Pascual ${ }^{143}$, y, en este último, por cierto, se nos dice que, con la significación de 'arenas movedizas', barrial tiene vigencia en los territorios leonés y andaluz. Respecto a su uso en territorio leonés podemos decir que, efectivamente, barrial 'barrizal, cenagal, tollero' es voz registrada en Bercianos del Real Camino (León) ${ }^{144}$ y en Flores de Aliste ${ }^{145}$. Y también barrial 'barrizal' aparece en cuatro puntos de Andalucía occidental (uno, de Huelva; otro, de Sevilla; otro, de Cádiz; y el último, del suroeste de Málaga) ${ }^{146}$. Barrial 'barrizal; lodazal; cenagal ; trampal' es, evidentemente, voz del área occidental del dominio lingüístico español, llevada luego a América por leoneses, extremeños y andaluces occidentales.

Badén fue una de las dos respuestas obtenidas en el pueblo abulense de Aldeavieja. En principio extraña el uso de badén con el significado de 'terreno pantanoso', pero es explicable, en parte, porque además del significado corriente hoy, badén tiene en la lengua estándar el de 'depresión por donde corren las aguas' ${ }^{147}$, y con la significación de 'arroyo seco que queda hecho de las corrientes de las aguas' aparece ya en el Diccionario de Autoridades ${ }^{148}$. Badén, en definitiva, significa 'charco, laguna, depresión llena de agua', y de este significado se pasa con facilidad al de 'terreno pantanoso', bajo la influencia de badonal/bodonal. Por otra parte, la dualidad de significados que encontramos en badén es la misma que existe, en el área oriental del dominio lingüístico español (Aragón, Andalucía oriental, sobre todo) respecto a la voz bache, que significa, indistintamente, 'hoyo, depresión, bache' y 'charco, depresión llena de agua, lavajo'.

\footnotetext{
139 Vid. Terreros, I, pág. 225.

$140 V$ id. $D R A E$, pág. 168.

141 Vid. Martín Alonso, I, pág. 652.

142 Vid. M. Moliner, I, pág. 352.

143 Vid. Corominas-Pascual, I, pág. 524.

$144 V$ id. Aguado, pág. 198.

$145 V$ id. Ferrero, pág. 51.

14 Vid. ALEA, IV, mapa 902.

$147 V$ id. DRAE, pág. $155 ; G$. de Diego, pág. 621.

148 Vid. Diccionario de Autoridades, I, pág. 528.
} 
En el pueblo salmantino de Alameda de Gardón fue registrada la voz guadaña, al lado de bonal, formas, ambas, muy salmantinas.

El uso de guadaña como sinónimo de bonal no puede llamar la atención porque en prácticamente toda la provincia de Salamanca se llama guadaña al prado de mejor calidad existente en cada finca o en cada dehesa o en cada propiedad, o incluso en cada pueblo, un prado situado en bajo, generalmente en una ribera, que está encharcado desde noviembre hasta mayo en los años normales desde el punto de vista de las precipitaciones acuosas. Por lo tanto, la guadaña está gran parte del año encharcada, "enchaguarzada" (como se dice en Salamanca), y no tiene nada de particular que en algún punto, como en Alameda de Gardón, o en algunos puntos, guadaña, además de 'prado húmedo y de buena calidad' haya pasado a significar 'terreno pantanoso'.

Es curioso que guadaña 'prado húmedo y de buena calidad', de uso tan frecuente en Salamanca, no aparezca en ningún repertorio, ni siquiera en los provinciales de Lamano y Fernández Gatta, hombres tan conocedores del campo y del habla de la provincia, ni tampoco en el monumental repertorio del también salmantino Martín Alonso Pedraz, lleno de palabras y acepciones salmantinas.

Si guadaña no aparece con el significado de 'prado húmedo y de buena calidad', menos se podía esperar que hubiera sido registrado con el de 'terreno pantanoso' que encontramos en Alameda de Gardón, acepción de alcance quizá sólo comarcal o local. De todas formas, la existencia en Salamanca de guadaña 'prado húmedo de buena calidad; terreno pantanoso', aunque se puede explicar como resultado de una síncopa o contracción de la lexía compleja prado de guadaña 'prado que se guadaña todos los años', inventariado en el $D R A E$, nos permite relacionar de manera directa guadaña (en las dos significaciones salmantinas) con la raiz germánica de la que también se ha derivado la palabra alemana Weide 'pradera, pastizal', sin tener que recurrir a una formación hecha sobre el verbo, asimismo de origen germánico, guadañar (de donde guadaña 'dalle').

$\mathrm{Y}$, por último, mesón, denominación del terreno pantanoso que encontramos en una sola localidad, en el pueblo zamorano de Villardiegua de la Ribera, en el extremo noroeste de Sayago.

No he podido encontrar la etimologia, y la explicación, de la voz mesón con este sorprendente significado. $\mathrm{Y}$, sin embargo, no es una creación local, ni un capricho del informador, ni siquiera una forma de alcance sólo comarcal, limitada al noroeste de Sayago, como podia suponerse sabiendo que mesón 'terreno pantanoso', además de en Villardiegua de la Ribera se usa también en el pueblo próximo de Villadepera de Sayago ${ }^{140}$ : resulta que

149 Vid. Borrego, pág. 78. 
mesón es palabra habitual, según Lamano, en la Tierra de Vitigudino (Salamanca), con el significado de 'tremedal, juncal, hondonal, malmuza (malmuza es otra interesante y típica voz salmantina, del mismo significado)' ${ }^{150}$; además, mesón fue recogida en la encuesta llevada a cabo en Villaseco de los Reyes (Salamanca, Tierra de Ledesma) con el significado de 'socavón a consecuencia de excesiva humedad o existencia de agua subterránea superficial'; y, por último, según mi experiencia personal, en el término de La Mata de Ledesma (dehesa de Porqueriza) hay un topónimo menor, El Mesón, referido a un paraje que presenta las características de todos los parajes aguachinosos que se encharcan con facilidad.

Por lo tanto, mesón 'terreno pantanoso; tremedal; terreno encharcado o encharcable' es voz extendida por un área que incluye Sayago, Tierra de Ledesma y Tierra de Vitigudino, por lo menos; una voz de carácter plenamente occidental, sobre cuya etimología nada podemos aventurar, y que hasta ahora. no ha sido registrada fuera de este pequeño rincón zamoranosalmantino marginal, tan interesante, todavía, desde el punto de vista lingüístico, el rincón donde se habló, y hoy en parte aún se habla, una modalidad leonesa rústica que inspiró el artificioso "sayagués" de muchos escritores de los siglos $\mathrm{xv}$-xvin.

150 Vid. Lamano, pág. 537. 